Article

\title{
Unexpected Reaction Pathway of the Alpha-Aminoalkyl Radical Derived from One-Electron Oxidation of $S$-Alkylglutathiones
}

\author{
Tomasz Pedzinski ${ }^{1,2} \oplus$, Krzysztof Bobrowski ${ }^{3,4} \oplus$, Bronislaw Marciniak ${ }^{1,2} \oplus$ and \\ Piotr Filipiak 1,2,*(D) \\ 1 Faculty of Chemistry, Adam Mickiewicz University, 61-614 Poznan, Poland; tomekp@amu.edu.pl (T.P.); \\ marcinia@amu.edu.pl (B.M.) \\ 2 Center for Advanced Technology, Adam Mickiewicz University, 61-614 Poznan, Poland \\ 3 Centre of Radiation Research and Technology, Institute of Nuclear Chemistry and Technology, \\ 03-195 Warsaw, Poland; kris@ichtj.pl \\ 4 Notre Dame Radiation Laboratory, University of Notre Dame, Notre Dame, IN 46556, USA \\ * Correspondence: piotrf@amu.edu.pl; Tel.: +48-61-829-1738
}

Received: 23 January 2020; Accepted: 12 February 2020; Published: 17 February 2020

check for updates

\begin{abstract}
Laser flash photolysis and high-resolution mass spectrometry were used to investigate the mechanism of one-electron oxidation of two S-alkylglutathiones using 3-carboxybenzophenone (3CB) as a photosensitizer. This report indicates an unexpected reaction pathway of the $\alpha$-aminoalkyl radical cation $\left(\alpha \mathrm{N}^{+}\right)$derived from the oxidation of $S$-alkylglutathiones. Instead of a common hydrolysis reaction of $\alpha \mathrm{N}^{+}$reported earlier for methionine and other sulfur-containing aminoacids and peptides, an intramolecular ring-closure reaction was found for $S$-alkylglutathiones.
\end{abstract}

Keywords: S-alkylglutathiones; one-electron oxidation; laser flash photolysis; decarboxylation

\section{Introduction}

S-alkylglutathiones, as thioethers derived from glutathione (Glu), are considered as biologically relevant peptides (naturally occurring oligopeptides). They occur in plants, animals, and humans [1]. For instance, S-methylglutathione (S-Me-Glu, Figure 1) was found in yeasts [2], brain tissues [2,3], and Escherichia coli [4]. In biological systems, the synthesis of S-Me-Glu involves chemotaxis methyltransferase, glutathione, and S-adenosyl-methionine [4]. In plants and animals, S-Me-Glu was found to be a metabolic product when various methylated drugs and pesticides were present [1]. When methyl halides are metabolized by glutathione S-transferases, S-Me-Glu is a common product [5]. Examples are methyl chloride [6,7], methyl bromide [5,8], and methyl iodide [5,9], where erythrocytes are metabolically conjugated with Glu to form S-Me-Glu in livers, brains, and kidneys of humans and certain rodents. The biological functions of $S$-alkylglutathiones were characterized fairly extensively [1]. Some of these biological functions of $S$-alkylglutathiones are the following: (i) acting as selective ligands of brain ionotropic glutamate receptors [10], (ii) inhibiting the glyoxylase cycle [11,12], and (iii) preventing inactivation of glutathione transferase [13]. S-Me-Glu inhibits S-nitrosoglutathione reduction mediated by alcohol dehydrogenase, although substituting the sulfhydryl proton of Glu by a methyl moiety hardly improved the inhibitory effect of Glu alone [14].

Recently, antioxidant properties of S-ethylglutathione (S-Et-Glu) with regard to functional rat heart disorders were reported [15]. In addition, it was found that S-Me-Glu can either regulate or modulate $N$-methyl-D-aspartates glutamate receptor responses [16], can support transendothelial fluid transport [17], and can effectively promote oxidation of DNA [18]. It is also of relevance to the 
presence of $S$-methylglutathione in yeasts that yeasts can substitute $S$-methylcysteine for cysteine in the synthetic pathway of glutathione [3].

In the light of such wide-spread biological activities of $S$-alkylglutathiones, any oxidative degradation of them by reactive oxygen species (ROS) and carbonyl triplets is of concern during oxidative stress $[17,19,20]$. This is the main motivation to study free radicals produced by oxidation of $S$-alkylglutathiones and to understand the fate of these radicals. It is in these chemical studies that fundamental issues arise in how neighboring groups can affect the fate of the sulfur-centered radicals that form early in these oxidations. This is the topic of this work.

One-electron oxidation of organic sulfides, such as $S$-alkylglutathiones, typically yields a monomeric sulfur-centered radical cation $\left(>S^{\bullet+}\right)$ as a primary product. Oxidation of the sulfur moiety is usually followed by the deprotonation at one of the two carbon atoms located in the $\alpha$ position to the sulfur atom, and a relatively stable carbon-centered $\alpha$-thioalkyl radical $(\alpha S)$ is formed. In a presence of electron-rich neighboring groups, however, this monomeric sulfur radical cation $\left(>S^{\bullet+}\right)$ can be also efficiently stabilized by the formation of inter- and intramolecular three-electron bonded species [21]. The radical cation $>S^{\bullet+}$ can interact with neighboring groups, which are even located over quite long distances. This was demonstrated during (i) ${ }^{\bullet} \mathrm{OH}$ radical induced oxidation of methionine residues containing peptides [22-28] and (ii) photoinduced one-electron oxidation of peptides containing Met residues by the 4-CB triplet state [29-31]. The S-Me-Glu radical cation studied in this work has been shown before to form a nine-membered cyclic structure (see Figure S4 in SI) with the participation of an amino group on the $\gamma$-Glu residue [22,31]. This intramolecular (S: $: \mathrm{N})$-bonded radical cation decays via decarboxylation of the $\gamma$-Glu residue, yielding $\mathrm{CO}_{2}$ and an $\alpha$-aminoalkyl radical $(\alpha \mathrm{N}$, see Figure S5 in SI for more details). On the other hand, some recent reports put the existence of the nine-membered cyclic intermediate into question, claiming that the stabilization of the sulfur radical cation is achieved through a ten-membered ring with a three-electron bond between the oxidized sulfur and an oxygen in the $\gamma$-Glu's carboxylic group [32].

This work is mainly focused on the reaction pathways of the $\alpha$-aminoalkyl radical derived from two S-alkylglutahiones with methyl and ethyl groups, which are formed as a result of decarboxylation of these tripeptides. This highly reducing species undergoes electron-transfer reactions (in the presence of potential oxidizing agents like benzophenone, PNAP, $\mathrm{MV}^{2+}$ ), yielding a resonance-stabilized carbocation, as reported for methionine [33]. The consecutive reactions of these carbocations and their products have never been reported to date, in peptides in particular, and they are studied here by means of high-resolution mass spectrometry coupled with HPLC and steady-state and time-resolved photolysis.

\section{yGlu S-Alk-Cys Gly}<smiles>CCCCC</smiles>

Figure 1. Structure of S-alkylglutathiones (S-Me-Glu and S-Et-Glu).

\section{Results}

\subsection{Laser Flash Photolysis}

The transients formed in the photosensitized oxidation of peptides containing thioether group are well characterized $[29,31,32,34-39]$. Photosensitized oxidation of $S$-alkylglutathiones leads to numerous radical transient products [31,32]. As schematically presented in Scheme SI in Supplementary 
Materials, the $355 \mathrm{~nm}$ laser photolysis of the investigated system leads to the formation of the 3-carboxybenzophenone triplet state $\left(3 \mathrm{CB}^{*}\right)$, which is collisionally quenched by either S-Me-Glu or S-Et-Glu, yielding 3-carboxybenzophenone radical anion $\left(3 \mathrm{CB}^{\bullet-}\right.$ ) (or 3-carboxybenzophenone ketyl radical $\left(3 \mathrm{CBH}^{\bullet}\right), \mathrm{pK}_{\mathrm{a}}=9.5$ [37]) and a monomeric S-centered radical cation $\left(>\mathrm{S}^{\bullet+}\right)$. After charge separation of the encounter complex, $>S^{\bullet+}$ is stabilized by numerous equilibria involving intermediates with (S.:O), (S.:S), and (S.:N) two-centered three-electron bonds. All these equilibria eventually lead to two irreversible reaction channels: (i) deprotonation of $>S^{\bullet+}$ at the carbon atoms adjacent to the sulfur yielding $\alpha$-(alkylthio)alkyl radicals $\alpha S$ and (ii) decarboxylation via the nine-membered sulfur-nitrogen three-electron bonded transient that yields $\alpha \mathrm{N}$ radicals (for more detailed mechanism see Scheme SI in Supplementary Materials).

The main intermediates involved in the formation of stable products, as detected by pulse radiolysis and/or laser flash photolysis methods, are the following: $3 \mathrm{CB}^{\bullet-}$ (ketyl radical anion), $\alpha \mathrm{S}$, and $\alpha \mathrm{N}$ radicals. The latter species, under laser photolysis conditions, can only be produced in basic solutions because it requires the formation of a three-electron bond between the oxidized sulfur atom, and the nitrogen atom containing a free electron pair (in neutral and acidic $\mathrm{pH}$, the amino group is protonated, and consequently no free electron pair is available to form the $\alpha \mathrm{N}$ precursor). These radicals can recombine forming stable products or be involved in more complex mechanisms, as described below.

The transient absorption spectra following $3 \mathrm{CB}$ triplet quenching by S-Me-Glu $(10 \mathrm{mM})$ in aqueous solution at $\mathrm{pH}=11.2$ are presented in Figure 2.

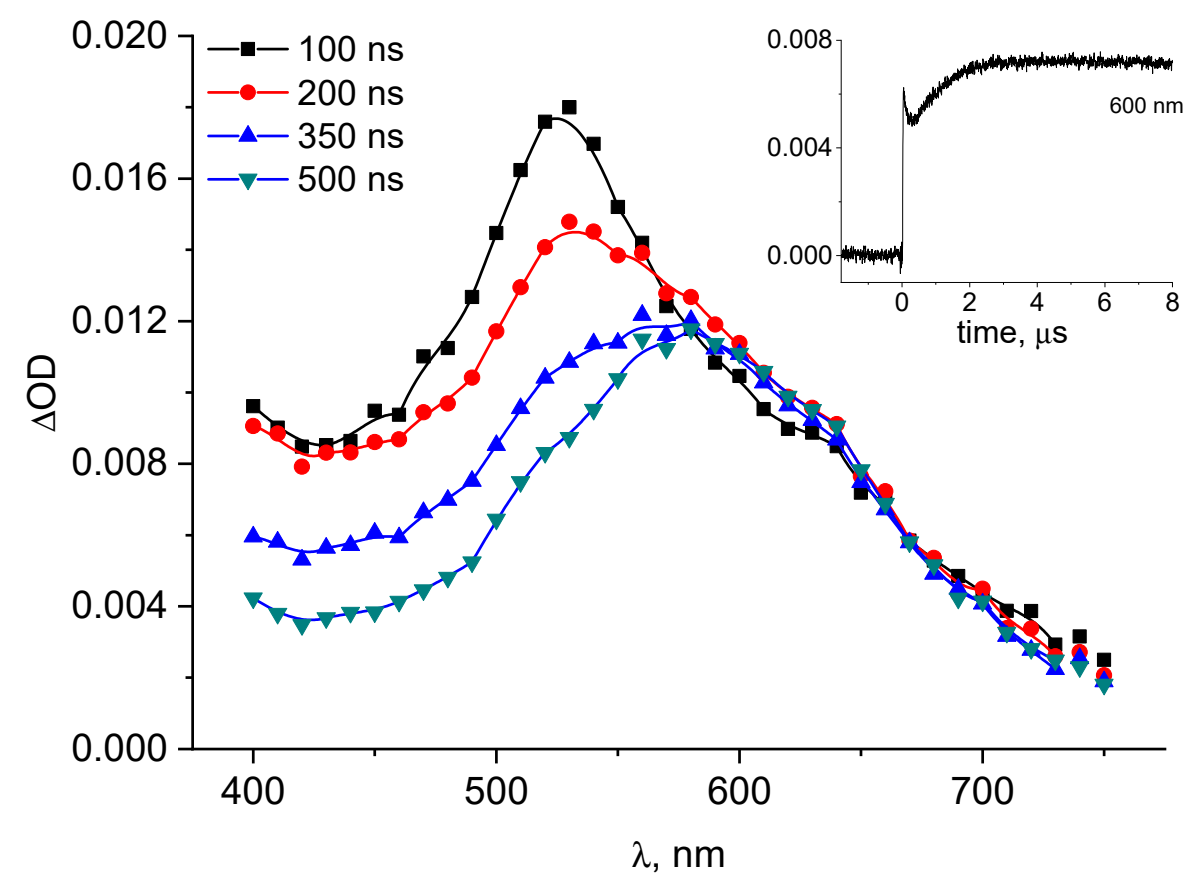

Figure 2. Transient absorption spectra following 3CB (4 mM) triplet photosensitized oxidation of S-MeGlu $(10 \mathrm{mM})$ at $\mathrm{pH}=11.2$. Inset: kinetics monitored at $\lambda=600 \mathrm{~nm}$ (absorption maximum of $3 \mathrm{CB}^{\bullet-}$ ).

The spectra clearly show the presence of the $3 \mathrm{CB}$ radical anion $\left(3 \mathrm{CB}^{\bullet-}\right)$ (with its typical absorption band characterized by $\lambda_{\max } \approx 600 \mathrm{~nm}$ ). Under these experimental conditions, the spectra of neither $\alpha \mathrm{S}$ nor $\alpha \mathrm{N}$ radicals could be recorded owing to the presence of the strongly absorbing 3CB ground state. It has been reported, however, that under pulse radiolysis conditions (in the absence of the photosensitizer) both radicals were observed with their absorptions in the UV region of 265-290 nm [40].

An indirect support for the formation of the $\alpha \mathrm{N}$ radical comes from the kinetic analysis of the $3 \mathrm{CB}^{\circ-}$ formation. Its initial fast growth is the result of the electron transfer between the two reactants in the primary quenching process, leading to the formation of intermediate radical pair (encounter complex 
$3 \mathrm{CB}^{\bullet-} \ldots{ }^{+\bullet} \mathrm{S}<$ ), which decays mainly via charge separation, forming $3 \mathrm{CB}^{\bullet-}$. The secondary, somewhat slower growth can be clearly seen in the inset to Figure 2. The nature of this slower secondary growth is attributed to an electron transfer from the $\alpha \mathrm{N}$ radical (which is known to be a highly reducing species) to the ground state sensitizer (3CB) [41], which occurs on a longer timescale and can be conveniently monitored at $600 \mathrm{~nm}$ (inset kinetic in Figure 2). This reaction (the electron transfer between $\alpha \mathrm{N}$ radical and 3CB) is shown in Scheme SI and leads to the formation of an $\alpha \mathrm{N}$ carbocation $\left(\alpha \mathrm{N}^{+}\right)$(stabilized by the resonance owing to the adjacent nitrogen atom) and $3 \mathrm{CB}^{\bullet-}$. Moreover, the amount of $3 \mathrm{CB}^{\bullet-}$ formed in the secondary reaction can be quantified based on the known molar absorption coefficient of this species $\left(\varepsilon_{600}=5200 \mathrm{M}^{-1} \mathrm{~cm}^{-1}\right.$ [37] $)$ and the analysis of the kinetic trace in the inset to Figure 2 . The concentration of $3 \mathrm{CB}^{\bullet-}$ formed in this secondary reaction was calculated to be $0.6 \mu \mathrm{M}$, and this value corresponds to the quantum yield of 0.24 , which is in a good agreement with the quantum yield of $\mathrm{CO}_{2}\left(\Phi_{\mathrm{CO} 2}=0.23\right.$ reported earlier [31]). The initially formed species with maximum at $520 \mathrm{~nm}$ is the 3CB triplet state, decaying because of the bimolecular quenching by S-Alk-Glu (as shown in Figure S3).

It is interesting to follow the reactions of this carbocation because such a reaction mechanism has never been reported before. According to the literature, the same $\alpha \mathrm{N}^{+}$cation moiety was proposed in analogous systems when the presence of $\alpha \mathrm{N}$ was probed by $\alpha \mathrm{N}$ reactions with PNAP (p-nitroacetophenone) [42] and $\mathrm{MV}^{2+}$ [33]. In our studies, 3CB plays essentially the same role as PNAP or $\mathrm{MV}^{2+}$ (both are electron acceptors) in their reactions with $\alpha \mathrm{N}$. Therefore, the presence of $\alpha \mathrm{N}^{+}$in the reaction scheme (see Scheme SI for more details) is plausible.

\subsection{Analysis of High-Resolution Mass Spectra}

The fate of such an $\alpha \mathrm{N}^{+}$transient can be deduced from an analysis of stable products carried out by means of high-resolution mass spectrometry. In earlier studies on methionine oxidation [42], it was suggested that the oxidized amino radical derived from methionine (depicted here as $\alpha \mathrm{N}^{+}$and existing in two resonance forms as presented in Scheme 1) is subjected to hydrolysis, yielding the corresponding aldehyde and ammonia (Scheme 1).

In the present studies, the presence of respective aldehyde was searched for by means of advanced LC-MS techniques. However, no traces of its formation were found. Interestingly, the other products were found, and the rationale for their formation is discussed in detail below.

As described above, the transients formed in the $S$-alkyl-Glu photooxidation are well characterized, but the reaction pathways leading to the stable products have not been well established. High resolution mass measurements performed on TOF (time-of-flight) analyzers allow for the determination of the molecular composition of the analyzed molecular ions (typically $\mathrm{MH}^{+}$) or fragment ions through the exact (monoisotopic) mass determination. One can also deduce the molecular composition of a neutral fragment loss by a simple subtraction of appropriate monoisotopic masses.

The samples containing aqueous solutions of S-Me-Glu or S-Et-Glu (10 mM) and 3CB (2 mM) at $\mathrm{pH}=11.2$ were irradiated using a $355 \mathrm{~nm} \mathrm{CW}$ laser (the excitation wavelength was chosen for selective excitation of the 3 CB sensitizer molecule). The irradiated samples were subjected to further LC-MS analysis.

The $m / z$ values were measured and interpreted for all of the chromatographic peaks presented in Figure 3. 


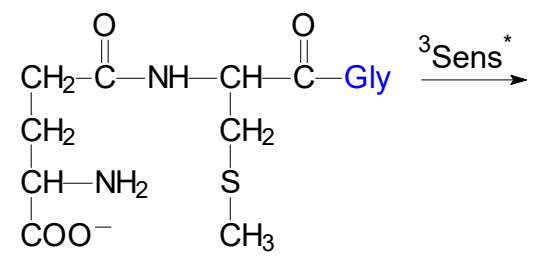

S-Me-Glu

$\mathrm{m} / \mathrm{z} 322$<smiles>C[I+][14CH3]</smiles>

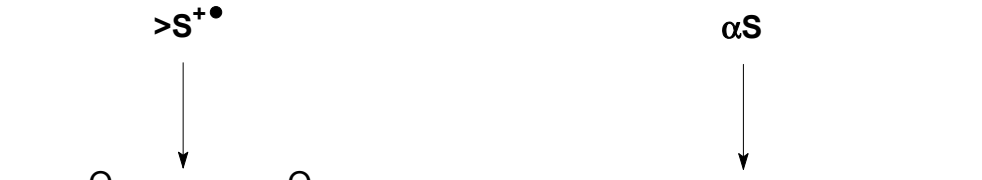<smiles>C[SH](CC(NC(=O)CCC(N)C(=O)[O-])C(=O)[O-])C(=O)OCc1ccccc1</smiles>

radical coupling reactions

P2 $\alpha$ S-Sens $\mathrm{m} / \mathrm{z} 548$

$\mathrm{P} 3 \alpha \mathrm{S}-\alpha \mathrm{S} \mathrm{m} / \mathrm{z} 641$

P4 Sens-Sens $\mathrm{m} / \mathrm{z} 455$<smiles>CSCC(NC(=O)CC[C@H](C)N)C(=O)C1CCCCC1</smiles>

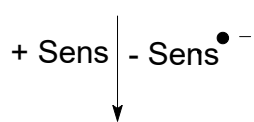
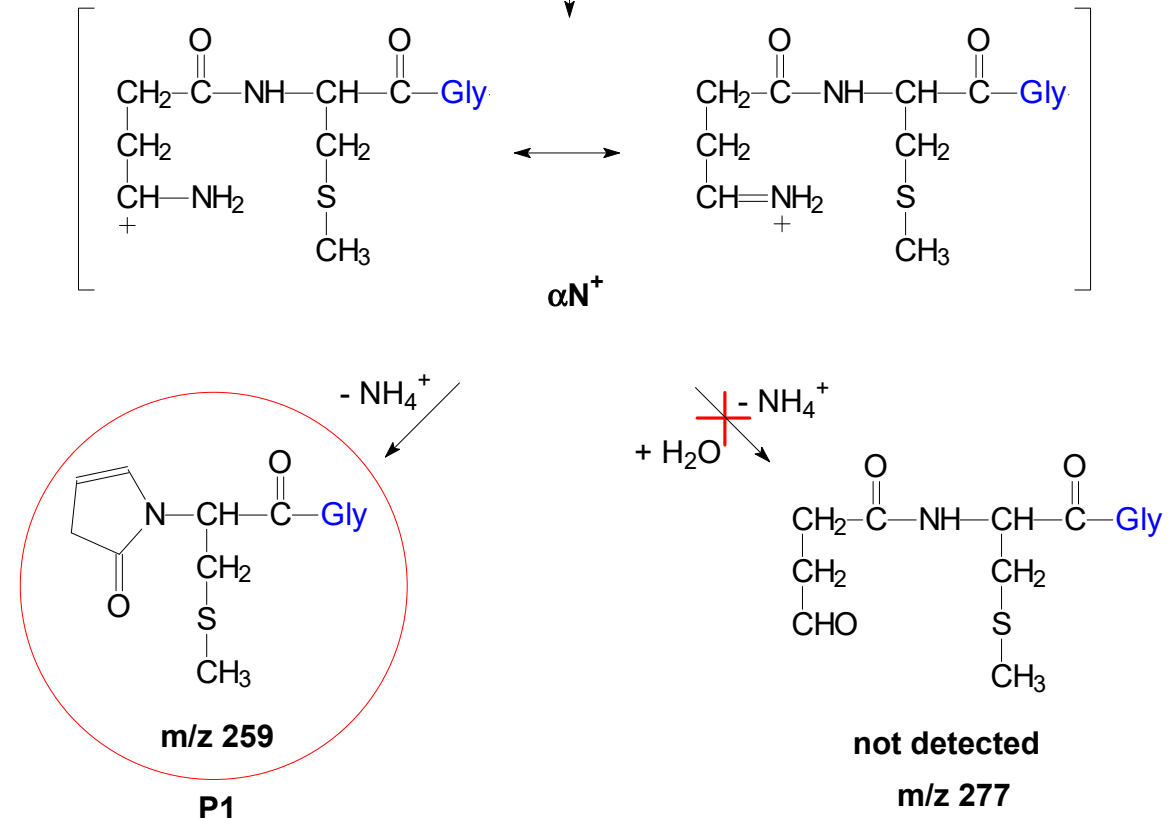

Scheme 1. Mechanism of short-lived intermediates and stable photoproducts formation for sensitized by 3CB photooxidation of S-Me-Glu at pH 11.2 (P2, P3, and P4 structures see Figure S6 in Supplementary Materials). 


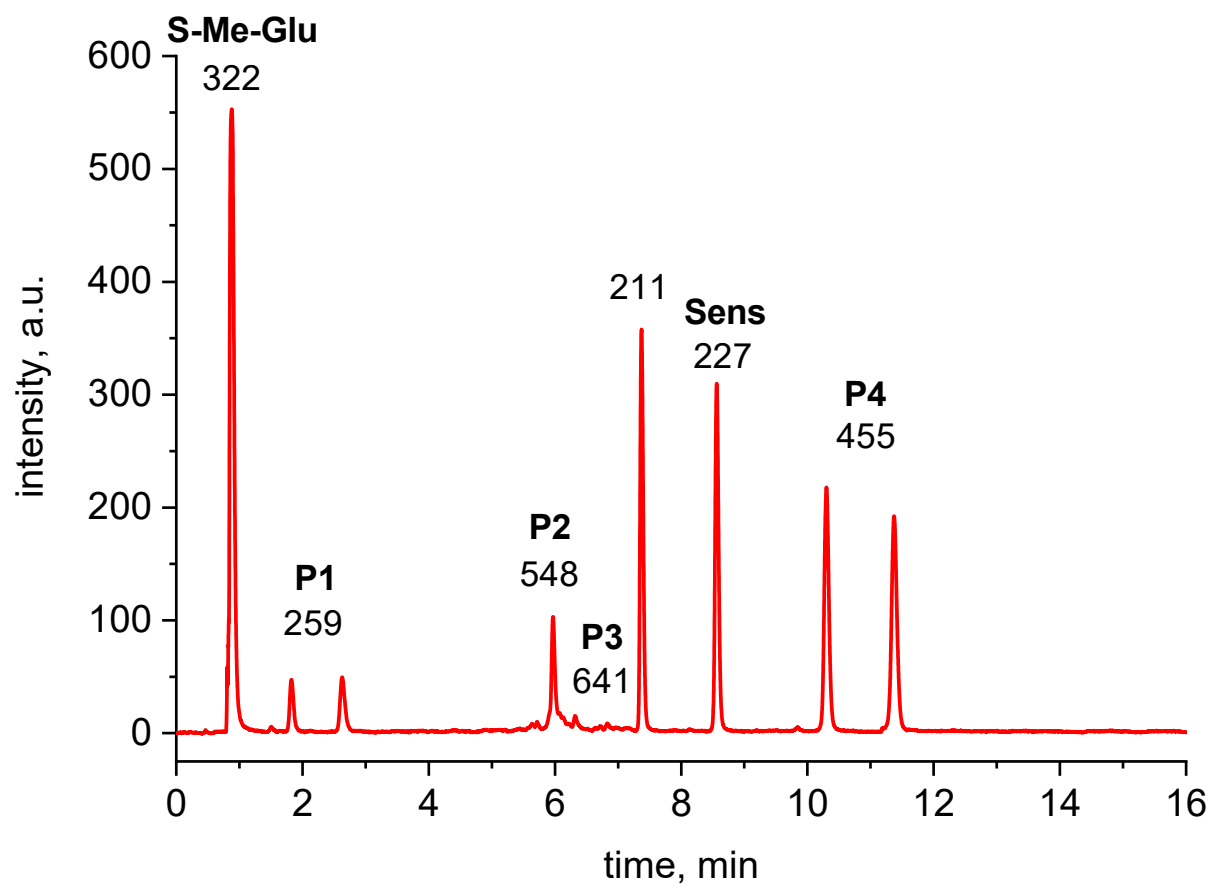

Figure 3. HPLC-MS chromatogram of $355 \mathrm{~nm}$ irradiated 3CB (2 mM) and S-Me-Glu (10 mM) mixture. Peaks are labelled with $\mathrm{m} / \mathrm{z}$ of the most intense peak of the acquired MS spectrum. For high-resolution $m / z$ values, see Table 1.

Table 1. High-resolution MS data for S-Me-Glu (first two rows) and S-Et-Glu (last two rows).

\begin{tabular}{ccccc}
\hline $\begin{array}{c}\text { MH } \\
\text { (Measured) }\end{array}$ & $\begin{array}{c}\text { MH }^{+} \text {Exact Mass } \\
\text { (Calculated) }\end{array}$ & $\begin{array}{c}\text { Most Abundant } \\
\text { Fragment (MSMS) }\end{array}$ & $\begin{array}{c}\text { Molecular } \\
\text { Composition }\left(\mathbf{M H}^{+}\right)\end{array}$ & Product \\
\hline 259.0759 & 259.0753 & 176.0382 & C10H15N2O4S & P1 \\
\hline 548.1726 & 548.1703 & - & C25H30N3O9S & P2 $(\alpha$ S-Sens $)$ \\
\hline 273.1003 & 273.0909 & 190.0540 & C11H17N2O4S & $\mathrm{P}^{\prime} 1$ \\
\hline 562.1864 & 562.1859 & - & C26H32N3O9S & $\mathrm{P}^{\prime} 2(\alpha S-S e n s)$ \\
\hline
\end{tabular}

For $m / z$ values and MS spectra of products derived from $3 \mathrm{CB}$, see Supplementary Information. P1/P2 products derived from the oxidation of S-Me-Glu; $\mathbf{P}^{\prime} \mathbf{1} / \mathbf{P}^{\prime} \mathbf{2}$ derived from S-Et-Glu.

The peaks with $\mathrm{m} / \mathrm{z} 322$ and 227 were assigned to the substrates, S-Me-Glu and 3CB, respectively. The peaks with $\mathrm{m} / z 211$ and 455 were assigned to the products derived from the photosensitizer 3CB and are presented in Figure 3. The peaks with $m / z 548$ and 259 are relevant to S-Me-Glu oxidation, and they will be discussed in more detail. It is noteworthy that, as expected, traces of $\alpha \mathrm{S}-\alpha \mathrm{S}$ radical coupling products $(\mathrm{m} / \mathrm{z} 641)$ were also detected (see small peaks at retention times of 6-7 min in Figure 3), but these photoproducts were not subjected to MSMS analysis in this work owing to their small yields. The high-resolution mass spectra of the latter two peaks are presented in Figure 4. Each MS spectrum shows one dominant peak corresponding to an $\mathrm{MH}^{+}$ion, and no efficient fragmentation was observed. From $\mathrm{m} / \mathrm{z} 548.1726$, a molecular composition of $\mathrm{C} 25 \mathrm{H} 30 \mathrm{~N} 3 \mathrm{O} 9 \mathrm{~S}\left(\mathrm{MH}^{+}\right)$was formulated.

This composition can be assigned to a recombination product of two radicals: $3 \mathrm{CB}^{\bullet-}$ and the carbon-centered $\alpha \mathrm{S}$ radical from S-Me-Glu. Both radicals were detected earlier using time-resolved spectrophotometric detection [31] ( $\alpha \mathrm{S}$ in pulse radiolysis and $3 \mathrm{CB}^{\bullet-} / 3 \mathrm{CBH}^{\bullet}$ in laser flash photolysis). Both were shown to be relatively stable, decaying on the millisecond time domain. It is quite plausible that such C-centered radicals can diffuse together and eventually can combine to give the observed $\mathrm{m} / \mathrm{z}$ 548 stable product (see Figure S6 Supplementary Materials).

The nominal peak with $m / z 259$ (exact $\mathrm{MH}^{+}$mass $=259.0759$ ) is presented in Figure 3 chromatogram as showing up in two peaks having similar retention times $(\mathbf{P 1})$. Both peaks were assigned to a $\mathrm{MH}^{+}$ 
molecular composition of $\mathrm{C} 10 \mathrm{H} 15 \mathrm{~N} 2 \mathrm{O} 4 \mathrm{~S}$. Moreover, the fragmentation MSMS spectrum showed an intense fragmentation peak with $\mathrm{m} / z$ 176.0382 (C6H10NO3S), as illustrated in Figure 5.
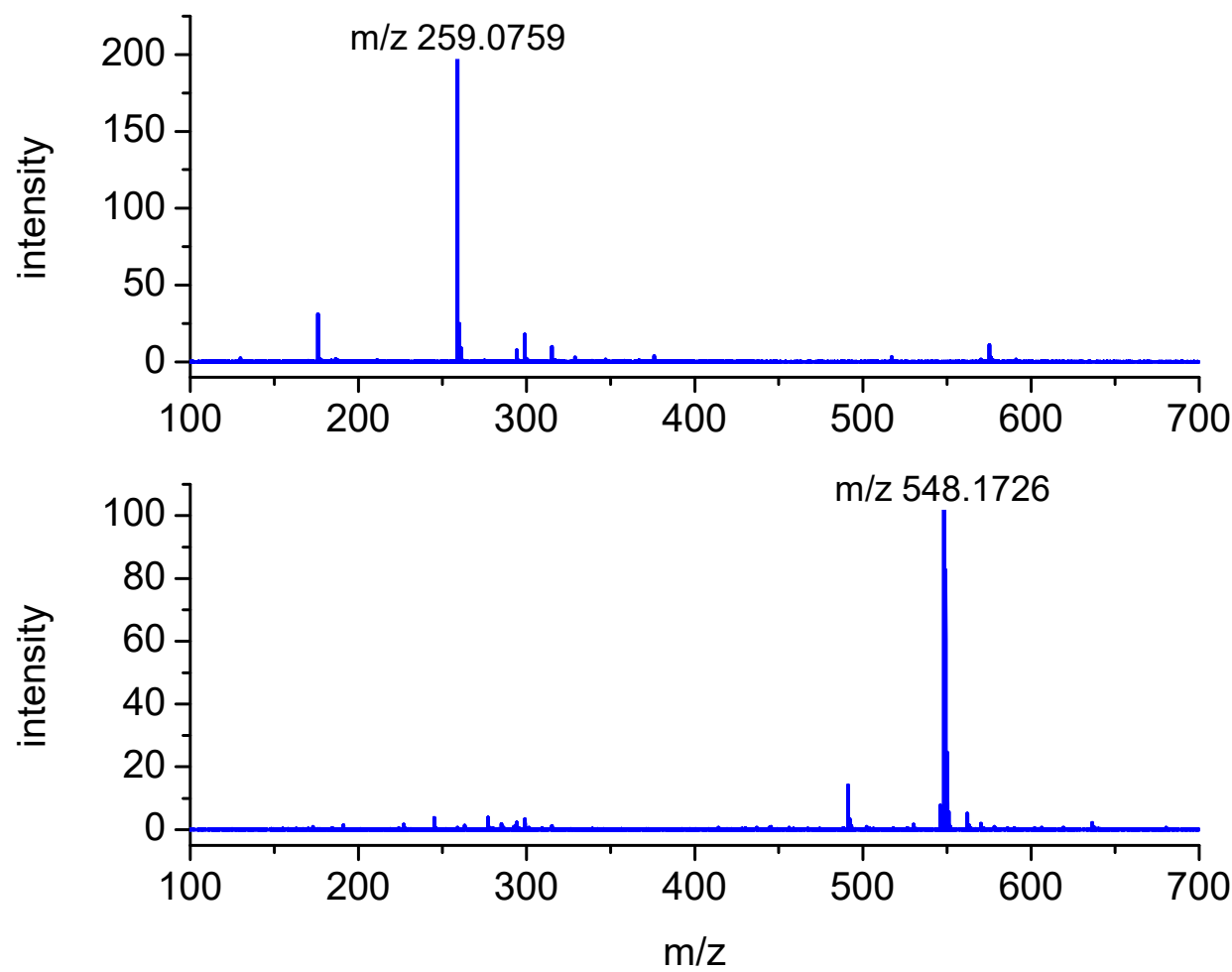

Figure 4. Mass spectra of the LC-MS peaks at retention times of $2.6 \mathrm{~min}$ (upper) and $6.0 \mathrm{~min}$ (lower) formed in the case of triplet 3CB-sensitized oxidation of S-Me-Glu (for more MS spectra, see Figure S2 in Supplementary Materials).

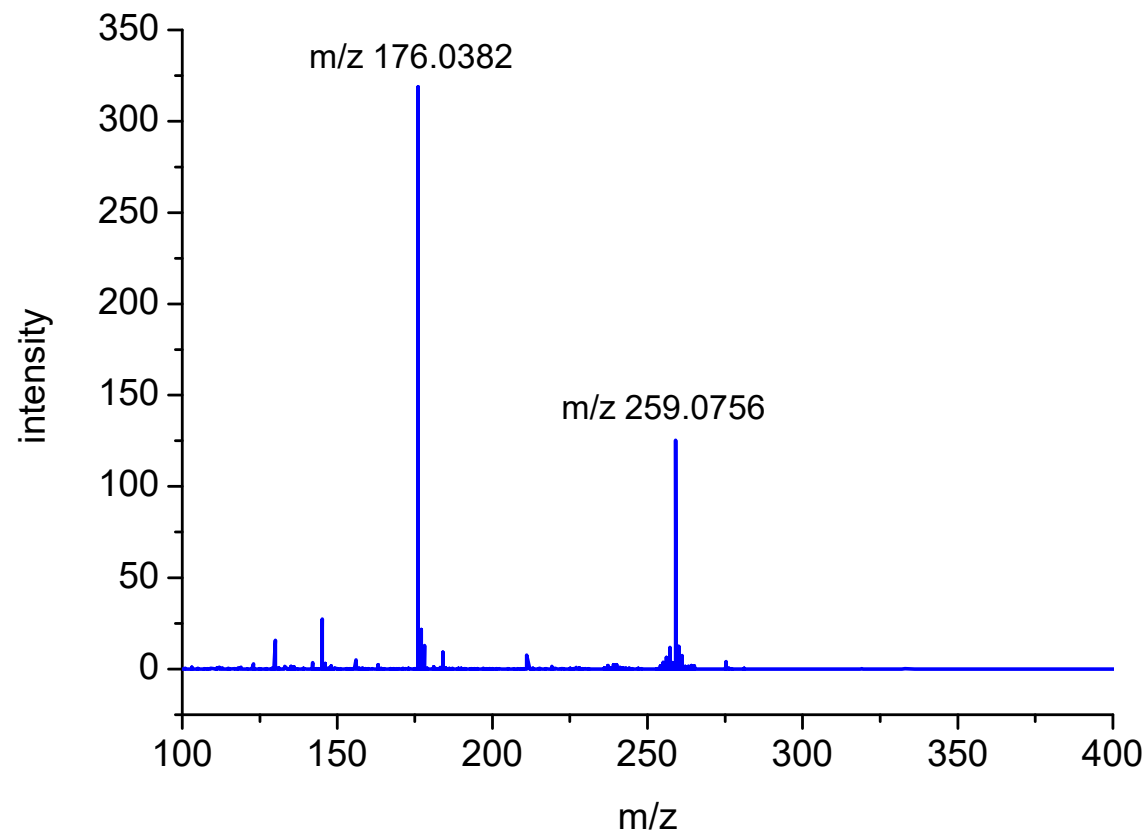

Figure 5. Fragmentation spectrum of $m / z 259$ ion (photoproduct P1) derived from oxidation of S-Me-Glu (electrospray ionization (ESI) source, capillary voltage $=4500 \mathrm{~V}$, collision energy $(\mathrm{CE})=10 \mathrm{eV}$ ). 
This corresponds to the loss of a neutral species of $\mathrm{C} 4 \mathrm{H} 5 \mathrm{NO}$. These observations suggest that these two peaks can be assigned to the isomeric structures of the same stable product (shown in Figure 6). A preliminary mechanism of its formation is presented in Scheme SI and Scheme SII (in Supplementary Materials) in details.
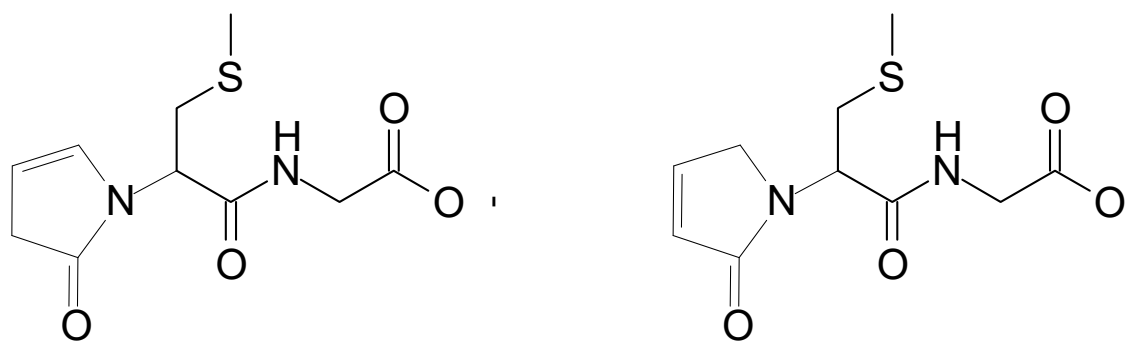

Figure 6. Suggested structures of isomeric products (depicted as P1, $m / z$ 259) derived from S-Me-Glu (similar products $\mathbf{P}^{\prime} \mathbf{1}$ derived from S-Et-Glu give $m / z$ 273-see Table 1 ).

The exact mass of the $\mathrm{m} / \mathrm{z}=548.1726$ peak corresponds to the molecular composition of C25H30N3O9S (see Table 1 for details). Such a formula suggests that this product results from the combination of the $\alpha S$ radical and the 3CB ketyl radical (see suggested structures in Figure S6 in Supplementary Materials).

The exact mass measurements (the calculated error is below $5 \mathrm{ppm}$ ) and the isotopic pattern (not shown) confirm the expected elemental composition of this product.

Similar reaction pathways were observed in the case of triplet 3CB-sensitized oxidation of S-Et-Glu, where the corresponding $\mathrm{m} / \mathrm{z}$ values were larger by 14 owing to the additional $-\mathrm{CH}_{2}-$ group present in this molecule (see Table 1 for MS data).

\section{Discussion}

\section{Mechanism}

The postulated fate of the $\alpha \mathrm{N}^{+}$carbocation is presented in Scheme SI. As already discussed above, the presence of such carbocations was suggested earlier in methionine oxidation, where they were found to react with water, eventually forming corresponding aldehyde [33]. A review paper on carbocations reactivity [43] shows that carbocations are generally good electron acceptors. However, for certain systems (even though electron transfer to the cations is favorably exothermic), the process does occur to any significant extent. As presented in Scheme SI (and more detailed in Scheme SII from the Supplementary Materials), the $\alpha \mathrm{N}^{+}$carbocation (resulting from the oxidation of the $\alpha \mathrm{N}$ radical) can interact with the peptidic nitrogen, forming a five-membered ring structure. Following the formation of this cyclic structure, intramolecular proton transfer can occur between the nitrogen atoms, followed by the elimination of ammonia. In alkaline conditions (note that only at basic $\mathrm{pH}$ can this reaction take place), it is likely that this reaction will be followed by deprotonation, yielding the final, stable peptide modification. The product of $m / z=259$ (or 273 for S-Et-Glu) can have two isomers because of a possible migration of the carbocation in the newly formed cyclic structure (Figure 6).

The P1 (and $\mathbf{P}^{\prime} \mathbf{1}$ ) photoproducts presented in Figure 6 were not produced efficiently after irradiation at neutral $\mathrm{pH}$, and only their trace amounts were found (see chromatogram for the $\mathrm{pH}=6$ in Figure S1 in Supplementary Materials). This result is consistent with our previous observations showing that decarboxylation does not occur efficiently at $\mathrm{pHs}$ below the $\mathrm{p} K_{\mathrm{a}}$ of the amino group in the $\gamma$-Glu residue of S-Me-Glu $\left(\mathrm{p} K_{\mathrm{a}}=8.7\right)$ [31]. In the absence of decarboxylation at $\mathrm{pH} 6$, the $\alpha \mathrm{N}$ radical cannot be formed, and consequently the reaction described above in Scheme SI for alkaline solutions does not occur efficiently at $\mathrm{pH}$ close to neutral.

Contrary to our consistent results, it was recently postulated [32] that decarboxylation proceeds via a 10-membered ring (presented in Figure S7 in Supplementary Materials) with participation of 
an oxygen atom in the carboxylic group and the respective (S:O)-bonded transient as a precursor. As the carboxylic group is deprotonated at both $\mathrm{pH}$ values in our experiments ( $\mathrm{pH}=6.0$ and 11.2), no difference in decarboxylation yields should be observed. However, our experimental results indicate the difference in the reaction pattern depending on $\mathrm{pH}$ in spite of the fact that the carboxyl group is deprotonated at both pHs. Following the same line of reasoning, the nitrogen atom located in the amino group is protonated at $\mathrm{pH} 6$ and deprotonated at $\mathrm{pH}$ 11.2. This fact supports the notion that the nitrogen atom participates in the stabilization of the sulfur radical cation (a precursor for decarboxylation).

Moreover, it has been demonstrated (e.g. with 3-methylthiopropionic acid) that the (S.:O)-bonded transients, although frequently formed in similar systems, cannot be precursors for decarboxylation. In other words, decarboxylation must be preceded by the formation of the (S.:N) ${ }^{+}$transient [44].

\section{Materials and Methods}

\subsection{Nanosecond Laser Flash Photolysis (LFP)}

Nanosecond laser flash photolysis experiments were performed using 3-carboxybenzophenone (3CB) as a photosensitizer. The setup has been described in detail elsewhere [38]. Briefly, this setup uses a Nd:YAG laser with its third harmonic $355 \mathrm{~nm}$ excitation wavelength as a pump (Spectra-Physics, Mountain View, CA, USA) and a pulsed Xe lamp to probe the excited sample. The laser pulse energy used in LFP experiments was set to $3 \mathrm{~mJ}$ (higher pulse energies could induce undesired multiphotonic processes). All flash photolysis experiments were carried out in $1 \times 1 \mathrm{~cm}$ rectangular quartz fluorescence cells and the absorbances of solutions at $355 \mathrm{~nm}$ (excitation wavelength) were set to approximately $\mathrm{A}_{355}=0.4$. The concentration of the quencher (S-Alk-Glu) was $10 \mathrm{mM}$. Kinetic traces were taken between 360 and 750 at $10 \mathrm{~nm}$ intervals. The time-resolved absorption spectra were constructed from kinetic traces.

\subsection{Preparation of Solutions}

All solutions were prepared in purified water. The $\mathrm{pH}$ of solutions was adjusted by adding potassium hydroxide and/or perchloric acid using a Mettler Toledo Five Easy FE20 pH-meter equipped with a semimicro InLab electrode from Mettler Toledo (Columbus, $\mathrm{OH}, \mathrm{USA}$ ). Aqueous solutions (unbuffered) were prepared shortly prior to each experiment and were deoxygenated by bubbling high-purity argon through them for at least $15 \mathrm{~min}$. The solutions were stirred during the experiments.

\subsection{Steady-State Photolysis}

Steady-state photolysis experiments were performed in a $1 \times 1 \mathrm{~cm}$ rectangular cell on an optical bench irradiation system using a Genesis CX355STM OPSL laser from Coherent (Santa Clara, CA, USA), with $355 \mathrm{~nm}$ emission wavelength (the output power used was set at $50 \mathrm{~mW}$ ). The concentrations of 3CB and S-Alk-Glu were $4 \mathrm{mM}$ and $10 \mathrm{mM}$, respectively.

\subsection{Chemicals}

3CB, S-Me-Glu, and S-Et-Glu were purchased from Sigma-Aldrich (St. Louis, MO, USA) and used as received. Water was purified through a Millipore (Merck Milli-Q) system. High purity argon (Linde) was used to purge the freshly prepared solutions of the reagents for photolysis experiments.

\subsection{LC-MS Measurements}

The LC-MS measurements were carried out using a liquid chromatography Thermo Scientific/ Dionex Ultimate 3000 (Waltham, MA, USA) system with a quaternary pump, membrane degasser, autosampler, temperature-controlled column compartment, and diode-array detector. The LC method employs a binary gradient of acetonitrile and water with $0.1 \%(v / v)$ formic acid. The LC separation was carried out on a Thermo Scientific Accucore ${ }^{\mathrm{TM}} \mathrm{C} 18$ reversed-phase column $(100 \times 2.1 \mathrm{~mm}, 2.6 \mu \mathrm{m}$ 
particle size) at a flow rate of $0.3 \mathrm{~mL} / \mathrm{min}$. This UHPLC system was coupled to a hybrid time-of-flight mass spectrometer (Impact, Bruker, Billerica, MA, USA) via an electrospray ionization (ESI) source operated in positive ion mode. Ions were generated by ESI under the following conditions: a flow rate of $0.3 \mathrm{~mL} / \mathrm{min}$, a nebulizer pressure of $1.5 \mathrm{bar}$, a spray voltage of $5200 \mathrm{~V}$, and a drying gas temperature of $200{ }^{\circ} \mathrm{C}$.

\section{Conclusions}

In the current paper, we provide an experimental proof for reaction pathways of two major C-centered radicals formed in the photosensitized oxidation of S-Me-Glu and S-Et-Glu in the presence of 3CB. The $\alpha$-thioalkyl radicals $(\alpha S)$ are formed as a result of deprotonation of the oxidized peptide $\left(>S^{\bullet+}\right)$, yielding the radical coupling products $\mathbf{P} 2$ and $\mathbf{P} 3$. The $\alpha$-aminoalkyl radicals $(\alpha \mathrm{N})$, resulting from decarboxylation, were observed exclusively at basic $\mathrm{pH}$. Its negligible amounts at neutral $\mathrm{pH}$ can be rationalized by the absence of its precursor (the $(S: \therefore)^{+}$radical cation). At $\mathrm{pH}=6.0$, the $(\mathrm{S}: \mathrm{N})^{+}$ radical cation cannot be formed because of the protonation of the amino group and the lack of an electron lone pair on the nitrogen atom necessary to form a $2 c-3 e(S: N)$ bond. In the presence of $3 C B$, the highly reducing $\alpha$-aminoalkyl radical $(\alpha \mathrm{N})$ undergoes an electron-transfer reaction, yielding a resonance-stabilized carbocation $\left(\alpha \mathrm{N}^{+}\right)$. The latter species, instead of hydrolysis reaction leading to an aldehyde, undergoes an unexpected competitive intramolecular ring-closure reaction, forming stable isomeric products at $m / z 259$ (P1) for S-Me-Glu (and $\mathbf{P}^{\prime} \mathbf{1} \mathrm{m} / z 273$ for S-Et-Glu). This reaction pathway, leading to stable peptide modifications, is reported here for the first time.

The formation of the cyclic structure from the oxidized $\alpha \mathrm{N}$ radical can be used as a probe for decarboxylation of $S$-alkylglutathiones and other peptides of a similar structure. It should be noted that, because the reaction described above can only proceed from the carbocation adjacent to the amino group (and not directly from the $\alpha \mathrm{N}$ radical), there must be an oxidizing agent, such as $3 \mathrm{CB}$, present in the investigated system.

As excited carbonyl compounds can be produced "in vivo" [20,45], similar reactions to those investigated in this work can potentially take place in real biological systems and for a variety of sulfur-containing peptides and proteins that exist in nature.

Supplementary Materials: The following are available online at http://www.mdpi.com/1420-3049/25/4/877/s1, Figure S1: HPLC-DAD chromatogram of non-irradiated (upper) and irradiated for 10 minutes (lower) 3CB $(3 \mathrm{mM})$-S-Me-Glu $(10 \mathrm{mM})$ system at $\mathrm{pH}$ 6.0. Only traces (as compared with $\mathrm{pH} 11$ ) of the irradiation products at $\mathrm{m} / \mathrm{z} 259$ can be seen at retention time of approximately $2.5 \mathrm{~min}$. Figure S2: 3CB + S-Me-Glu, irradiation time $10 \mathrm{~min}-$ Mass spectra of the LC-MS chromatogram for all detected peaks with their retention times. Figure S3. LFP kinetic traces monitored at $520 \mathrm{~nm}(\mathrm{~A})$ and $600 \mathrm{~nm}(\mathrm{~B})$. The 3CB triplet state is quenched efficiently by S-Me-Glu, shortening its lifetime to approximately $100 \mathrm{~ns}([3 \mathrm{CB}]=4 \mathrm{mM},[\mathrm{S}-\mathrm{Me}-\mathrm{Glu}]=10 \mathrm{mM}, \mathrm{pH}=11.2)$. Figure S4: Structure of a 9-membered cyclic (S: $: \mathrm{N})$-bonded radical cation. Figure S5: Structure of $\alpha$-aminoalkyl radical derived from S-methylglutathione (S-Me-Glu). Scheme SI: Mechanism of primary reactions in 3CB sensitized photooxidation of S-Me-Glu at $\mathrm{pH}=11.2$. Figure S6: Suggested structures of products: P2 $\mathrm{m} / \mathrm{z} 548$-adduct of S-Me-Glu $\alpha$-thioalkyl radical $(\alpha S)$ with 3CB ketyl radical; P3 $m / z 641-\alpha$ S radical dimer; P4 m/z 455-3CB ketyl radical dimer. Scheme SII: Suggested mechanism of cyclic product formation from the $\alpha \mathrm{N}+$ derived from S-Me-Glu. Figure S7: Structure of a 10-membered cyclic (S: $: O)$-bonded transient postulated in the work of [32].

Author Contributions: Conceptualization, B.M. and P.F.; formal analysis, T.P., B.M., K.B., and P.F.; funding acquisition, B.M. and P.F.; investigation, T.P. and P.F.; methodology, T.P. and P.F.; validation, K.B. and B.M.; writing-original draft preparation, T.P. and P.F.; writing—review and editing, B.M. and K.B. All authors have read and agreed to the published version of the manuscript.

Funding: This research was funded by the National Science Centre Poland within grants no. UMO-2013/11/B/ ST4/00811 and UMO-2017/27/B/ST4/00375.

Acknowledgments: P.F. and B.M. acknowledge the National Science Centre Poland for financial support mentioned above. K.B. gratefully acknowledges the Notre Dame Radiation Laboratory staff and personally Professor Ian Carmichael for the hospitality during his stay in the NDRL supported by DOE BES through grant number DE-FC02-04ER15533. All of us would like to thank Dr. Gordon L. Hug from the Notre Dame Radiation Laboratory for fruitful discussions and assistance in correction of the manuscript. This contribution is NDRL-5258 from the Notre Dame Radiation Laboratory.

Conflicts of Interest: The authors declare no conflict of interest. 


\section{References}

1. Maw, G.A. Biochemistry of S-methyl-L-cysteine and its principal derivatives. Sulfur Rep. 1982, 2, 1-26. [CrossRef]

2. Kanazawa, A.; Kakimoto, Y.; Nakajima, T.; Sano, I. Identification of $\gamma$-glutamylserine, $\gamma$-glutamylalanine, $\gamma$-glutamylvaline and S-methylglutathione of bovine brain. Biochim. Et Biophys. Acta (Bba) - Gen. Subj. 1965, 111, 90-95. [CrossRef]

3. Maw, G.A.; Coyne, C.M. The metabolism of S-methylcysteine in yeasts. Arch. Biochem. Biophys. 1968, 127, 241-251. [CrossRef]

4. Terwilliger, T.C.; Bollag, G.E.; Sternberg, D.W.; Koshland, D.E. S-methyl glutathione synthesis is catalyzed by the cheR methyltransferase in Escherichia coli. J. Bacteriol. 1986, 165, 958-963. [CrossRef] [PubMed]

5. Hallier, E.; Deutschmann, S.; Reichel, C.; Bolt, H.M.; Peter, H. A comparative investigation of the metabolism of methyl bromide and methyl iodide in human erythrocytes. Int. Arch. Occup. Environ. Health 1990, 62, 221-225. [CrossRef] [PubMed]

6. Peter, H.; Deutschmann, S.; Reichel, C.; Hallier, E. Metabolism of methyl chloride by human erythrocytes. Arch. Toxicol. 1989, 63, 351-355. [CrossRef]

7. Redford-Ellis, M.; Gowenlock, A.H. Studies on the reaction of chloromethane with preparations of liver, brain and kidney. Acta Pharmacol. Et Toxicol. 1971, 30, 49-58. [CrossRef]

8. Medinsky, M.A.; Bond, J.A.; Dutcher, J.S.; Birnbaum, L.S. Disposition of [14C] methyl bromide in fischer-344 rats after oral or intraperitoneal administration. Toxicology 1984, 32, 187-196. [CrossRef]

9. Johnson, M.K. Studies on glutathione S-alkyltransferase of the rat. Biochem. J. 1966, 98, 44-56. [CrossRef]

10. Jenei, Z.; Janáky, R.; Varga, V.; Saransaari, P.; Oja, S.S. Interference of S-alkyl derivatives of glutathione with brain ionotropic glutamate receptors. Neurochem. Res. 1998, 23, 1085-1091. [CrossRef]

11. Elango, N.; Janaki, S.; Rao, A.R. Two affinity chromatography methods for the purification of glyoxalase I from rabbit liver. Biochem. Biophys. Res. Commun. 1978, 83, 1388-1395. [CrossRef]

12. Vince, R.; Daluge, S.; Wadd, W.B. Inhibition of glyoxalase I by S-substituted glutathiones. J. Med. Chem. 1971, 14, 402-404. [CrossRef] [PubMed]

13. Di Ilio, C.; Sacchetta, P.; Angelucci, S.; Bucciarelli, T.; Pennelli, A.; Mazzetti, A.P.; Lo Bello, M.; Aceto, A. Interaction of glutathione transferase P1-1 with captan and captafol. Biochem. Pharmacol. 1996, 52, 43-48. [CrossRef]

14. Staab, C.A.; Hellgren, M.; Grafström, R.C.; Höög, J.-O. Medium-chain fatty acids and glutathione derivatives as inhibitors of S-nitrosoglutathione reduction mediated by alcohol dehydrogenase 3. Chem. -Biol. Interact. 2009, 180, 113-118. [CrossRef] [PubMed]

15. Lakomkin, V.L.; Lukoshkova, E.V.; Abramov, A.A.; Ermishkin, V.V.; Kapelko, V.I. Protective action of ethylglutathione at hypoxia-reoxygenation of the heart: Role of glucose. Kardiologiya 2013, 53, 49-54.

16. Regan, R.F. Modulation of N-methyl-D-aspartate receptor responses with S-substituted derivatives of glutathione. US6329430B1, 17 August 2001.

17. Anderson, E.I.; Wright, D.D. Effects of S-methyl glutathione, S-methyl cysteine, and the concentration of oxidized glutathione on transendothelial fluid transport. Investig. Ophthalmol. Vis. Sci. 1980, 19, 684-686.

18. Spear, N.; Aust, S.D. Hydroxylation of deoxyguanosine in DNA by copper and thiols. Arch. Biochem. Biophys. 1995, 317, 142-148. [CrossRef]

19. Cilento, G.; Nascimento, A.L.T.O. Generation of electronically excited triplet species at the cellular level: A potential source of genotoxicity. Toxicol. Lett. 1993, 67, 17-28. [CrossRef]

20. Cilento, G. Generation of electronically excited triplet species in biochemical systems. In Pure and Applied Chemistry; Burrows, H., Stohner, J., Eds.; De Gruyter: Berlin, Germany, 1984; Volume 56, p. 1179.

21. Glass, R.S. Sulfur-Centered Reactive Intermediates in Chemistry and Biology; Plenum Press: New York, NY, USA, 1990; Volume 97, pp. 213-226.

22. Bobrowski, K.; Hug, G.L.; Pogocki, D.; Marciniak, B.; Schöneich, C. Sulfur radical cation-peptide bond complex in the one-electron oxidation of S-Methylglutathione. J. Am. Chem Soc. 2007, 129, 9236-9245. [CrossRef]

23. Filipiak, P.; Bobrowski, K.; Hug, G.L.; Pogocki, D.; Schoneich, C.; Marciniak, B. Formation of a three-electron sulfur-sulfur bond as a probe for interaction between side chains of methionine residues. J. Phys. Chem. B 2016, 120, 9732-9744. [CrossRef] 
24. Bobrowski, K.; Holcman, J. Formation and stability of intramolecular three-electron SN, SS, and SO bonds in one-electron-oxidized simple methionine peptides. Pulse radiolysis. J. Phys. Chem. 1989, 93, 6381-6387. [CrossRef]

25. Schoneich, C.; Zhao, F.; Madden, K.P.; Bobrowski, K. Side chain fragmentation of N-terminal threonine or serine residue induced through intramolecular proton transfer to hydroxy sulfuranyl radical formed at neighboring methionine in dipeptides. J. Am. Chem Soc. 1994, 116, 4641-4652. [CrossRef]

26. Hug, G.L.; Bobrowski, K.; Pogocki, D.; Hoerner, G.; Marciniak, B. Conformational influence on the type of stabilization of sulfur radical cations in cyclic peptides. Chemphyschem 2007, 8, 2202-2210. [CrossRef] [PubMed]

27. Bobrowski, K.; Hug, G.L.; Pogocki, D.; Marciniak, B.; Schoeneich, C. Stabilization of sulfide radical cations through complexation with the peptide bond: Mechanisms relevant to oxidation of proteins containing multiple methionine residues. J. Phys. Chem. B 2007, 111, 9608-9620. [CrossRef] [PubMed]

28. Bobrowski, K.; Houée-Levin, C.; Marciniak, B. Stabilization and reactions of sulfur radical cations: Relevance to one-electron oxidation of methionine in peptides and proteins. Chim. Int. J. Chem. 2008, 62, 728-734. [CrossRef]

29. Ignasiak, M.T.; Pedzinski, T.; Rusconi, F.; Filipiak, P.; Bobrowski, K.; Houee-Leyin, C.; Marciniak, B. Photosensitized oxidation of methionine-containing dipeptides. From the transients to the final products. J. Phys. Chem. B 2014, 118, 8549-8558. [CrossRef]

30. Filipiak, P.; Bobrowski, K.; Hug, G.L.; Pogocki, D.; Schoneich, C.; Marciniak, B. New insights into the reaction paths of 4-carboxybenzophenone triplet with oligopeptides containing $\mathrm{N}$ - and $\mathrm{C}$-terminal methionine residues. J. Phys. Chem. B 2017, 121, 5247-5258. [CrossRef]

31. Filipiak, P.; Hug, G.L.; Bobrowski, K.; Pedzinski, T.; Kozubek, H.; Marciniak, B. Sensitized photooxidation of S-methylglutathione in aqueous solution: Intramolecular (SO) and (SN) bonded species. J. Phys. Chem. B 2013, 117, 2359-2368. [CrossRef]

32. Morozova, O.B.; Panov, M.S.; Vieth, H.M.; Yurkovskaya, A.V. CIDNP study of sensitized photooxidation of S-methylcysteine and S-methylglutathione in aqueous solution. J. Photochem. Photobiol. A: Chem. 2016, 321, 90-98. [CrossRef]

33. Hiller, K.O.; Masloch, B.; Goebl, M.; Asmus, K.D. Mechanism of the hydroxyl radical induced oxidation of methionine in aqueous solution. J. Am. Chem Soc. 1981, 103, 2734-2743. [CrossRef]

34. Marciniak, B.; Hug, G.L.; Kozubek, H.; Bobrowski, K. Mechanism of 4-carboxybenzophenone-sensitized photooxidation of methionine-containing dipeptides and tripeptides in aqueous solution. J. Phys. Chem. 1995, 99, 13560-13568. [CrossRef]

35. Hug, G.L.; Marciniak, B.; Bobrowski, K. Sensitized photo-oxidation of sulfur-containing amino acids and peptides in aqueous solution. J. Photochem. Photobiol. A: Chem. 1996, 95, 81-88. [CrossRef]

36. Hug, G.L.; Bobrowski, K.; Kozubek, H.; Marciniak, B. Photo-oxidation of methionine-containing peptides by the 4-carboxybenzophenone triplet state in aqueous solution. Competition between intramolecular two-centered three-electron bonded (SS)+ and (SN)+ formation. Photochem. Photobiol. 2000, 72, 1-9. [CrossRef]

37. Pedzinski, T.; Bobrowski, K.; Ignasiak, M.; Kciuk, G.; Hug, G.L. Lewandowska-Andralojc, A.; Marciniak, B., 3-Carboxybenzophenone (3-CB) as an efficient sensitizer in the photooxidation of methionyl-leucine in aqueous solutions: Spectral, kinetic and acid-base properties of 3-CB derived transients. J. Photochem. Photobiol. A: Chem. 2014, 287, 1-7. [CrossRef]

38. Pedzinski, T.; Markiewicz, A.; Marciniak, B. Photosensitized oxidation of methionine derivatives. Laser flash photolysis studies. Res. Chem. Intermed. 2009, 35, 497-506. [CrossRef]

39. Hug, G.L.; Marciniak, B.; Bobrowski, K. Acid-base equilibria involved in secondary reactions following the 4-carboxybenzophenone sensitized photooxidation of methionylglycine in aqueous solution. Spectral and time resolution of the decaying (S therefore N)(+) radical cation. J. Phys. Chem. 1996, 100, 14914-14921. [CrossRef]

40. Hiller, K.O.; Asmus, K.D. Oxidation of methionine by $\mathrm{X}$ in aqueous solution and characterization of some three-electron bonded intermediates. A pulse radiolysis study. Int. J. Radiat. Biol. Relat. Stud. Phys. Chem. Med. 1981, 40, 583-595. [CrossRef] 
41. Bobrowski, K.; Marciniak, B.; Hug, G.L. 4-Carboxybenzophenone-sensitized photooxidation of sulfur-containing amino acids. Nanosecond laser flash photolysis and pulse radiolysis studies. J. Am. Chem Soc. 1992, 114, 10279-10288. [CrossRef]

42. Hiller, K.O.; Asmus, K.D. Formation and reduction reactions of alpha-amino radicals derived from methionine and its derivatives in aqueous solutions. J. Phys. Chem. 1983, 87, 3682-3688. [CrossRef]

43. Das, P.K. Transient carbocations and carbanions generated by laser flash photolysis and pulse radiolysis. Chem. Rev. 1993, 93, 119-144. [CrossRef]

44. Bobrowski, K.; Pogocki, D.; Schöneich, C. Oxidation of (carboxyalkyl)thiopropionic acid derivatives by hydroxyl radicals. Mechanisms and kinetics of competitive inter- and intramolecular formation of $\sigma$ - and $\sigma^{*}$-type sulfuranyl radicals. J. Phys. Chem. A 1998, 102, 10512-10521. [CrossRef]

45. Cilento, G. Photobiochemistry without light. Experientia 1988, 44, 572-576. [CrossRef] [PubMed]

Sample Availability: Samples of the compounds are available from the authors.

(C) 2020 by the authors. Licensee MDPI, Basel, Switzerland. This article is an open access article distributed under the terms and conditions of the Creative Commons Attribution (CC BY) license (http://creativecommons.org/licenses/by/4.0/). 